\title{
A Credibilidade do Testemunho da Criança Vítima de Abuso Sexual no Contexto Judiciário
}

The Credibility Of The Child Victim Of Sexual Abuse Testimony In The Judiciary Context

La Credibilidad Del Testimonio De Los Niños Víctimas De Abuso Sexual En El Contexto Judiciario

Consuelo Biacchi Eloy

Universidade Estadual Paulista Júlio de Mesquita Filho
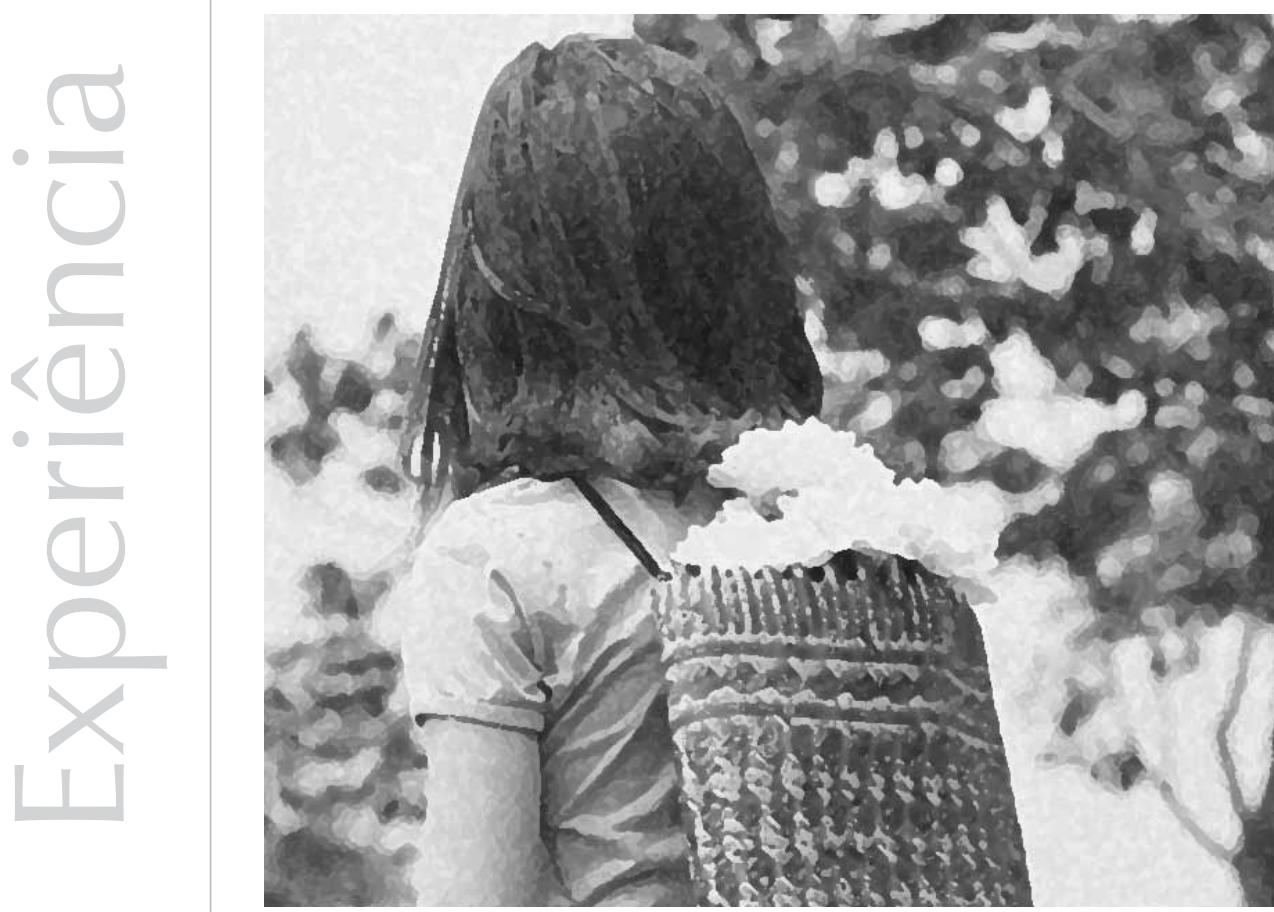
Resumo: Violência sexual contra crianças não é um evento incomum; no entanto, há a dificuldade de denúncia, pois, além do estabelecimento da relação de dominação que o agressor exerce sobre a vítima, a maneira como tal fato é recebido pela sociedade e como é encaminhado pelas instituições judiciárias responsáveis também é determinante para as omissões. Inserida no universo dos interrogatórios, muitas vezes, a criança causa confusão ao desmentir o que havia falado antes, reforçando possíveis preconceitos em relação a si mesma. O presente trabalho traz a análise das relações entre a infância e a instituição judiciária, com principal enfoque no sistema de comunicação e de notificação dos crimes sexuais contra a criança e as consequentes intervenções profissionais que buscam a validação, ou não, de seu testemunho. Para tanto, foram pesquisados 51 processos judiciais, dos quais foram selecionados dois casos exemplares. Este trabalho evidencia a possibilidade de preservar a criança da revitimização causada pela multiplicidade de interrogatórios, sem deixar de cumprir as normas jurídicas necessárias. A fragilidade da palavra da criança está na forma como é acolhida pelos adultos, desde a revelação na família até a denúncia aos órgãos oficiais, revelando a urgência de alterações nos procedimentos judiciais relacionados a essa problemática.

Palavras-chave: Abuso da criança. Psicologia forense. Comunicação interpessoal. Representação social.

Abstract: Sexual violence against children is not an uncommon event, however there is the difficulty of denunciation, for, besides the establishment of the domination relatios that the abuser has on the victim, the way it is received by society and is forwarded by the institution judicial officers is also decisive for the omissions. Inserted in the world of interrogations, the child often causes confusion to deny what was said before, reinforcing the possible prejudices against him/her. This work contains the analysis of the relationship between children and the judicial institution, with main focus in the communication and reporting system of sexual crimes against children and the consequent professional interventions that seek to validate or not their testimony. To this end, 51 lawsuits were surveyed, of which two cases were selected. This work shows the possibility of preserving the child's victimization caused by the multiplicity of interrogation without failing to meet the legal standards required. The fragility of the child's word is in the way it is received by adults, since the revelation to the family up to the denunciation to the official agencies, what reveals the urgency of changes in the judicial proceedings related to this issue.

Keywords: Child abuse. Forense psychology. Interpessoal communication. Social representation.

Resumen: La violencia sexual contra niños no es un evento poco común; sin embargo, existe la dificultad de denuncia, pues, además del establecimiento de la relación de dominación que el agresor ejerce sobre la víctima, la manera como tal hecho es recibido por la sociedad y cómo es encaminado por las instituciones judiciarias responsables también es determinante para las omisiones. Inserida en el universo de los interrogatorios, muchas veces, el niño causa confusión, al desmentir lo que había dicho antes, reforzando posibles prejuicios en relación a sí. El presente trabajo trae el análisis de las relaciones entre la infancia y la institución judiciaria, con principal enfoque en el sistema de comunicación y notificación de los crímenes sexuales contra niños y las consecuentes intervenciones profesionales que buscan la validación, o no, de su testimonio. Para tanto, fueron pesquisados 51 procesos judiciales, de los cuales fueron seleccionados dos casos ejemplares. Este trabajo evidencia la posibilidad de preservar al niño del aumento de la victimización causada por la multiplicidad de interrogatorios, sin dejar de cumplir las normas jurídicas necesarias. La fragilidad de la palabra del niño está en la forma como es acogida por los adultos, desde la revelación en la familia hasta la denuncia a los órganos oficiales, revelando la urgencia de alteraciones en los procedimientos judiciales relacionados a esa problemática.

Palabras clave: Abuso del niño. Psicología forense. Comunicación interpersonal. Representación social.

\begin{abstract}
A inserção da Psicologia no Poder Judiciário propiciou uma nova relação entre a Justiça e a infância, uma vez que sua atuação, desde a implantação do Estatuto da Criança e do Adolescente, se direciona aos assuntos afetos a essa área do Direito. A Psicologia, como mediadora entre a criança e o contexto judiciário, participa da trajetória histórica da infância brasileira, exigindo do profissional um compromisso ético e uma boa qualidade de escuta. Na especificidade desse contexto,
\end{abstract}

no qual as demandas diárias são bastante complexas e exigem respostas sobre a criança e sua subjetividade, foi que surgiu a motivação para uma pesquisa relacionada à credibilidade do testemunho da vítima infantil nos crimes sexuais.

O enfoque principal da pesquisa contempla a trajetória percorrida entre a suspeita e a validação do abuso sexual infantil, partindo do discurso da criança e do discurso daqueles que 
a interrogam. A análise, portanto, foi realizada desde a revelação até a sentença judicial, evidenciando as diferentes possibilidades de intervenção profissional a que a criança, habitualmente, é submetida. No âmbito judiciário, além de toda a complexidade que o fenômeno do abuso sexual suscita, há que se pensar na responsabilização penal do acusado e na garantia à criança de proteção e benefícios.

Na cultura brasileira, a sexualidade é um tema interdito para a infância. e, quando a criança se vê frente às intervenções policiais e judiciárias, nem sempre encontra acolhimento adequado e eficaz que lhe ofereça segurança para sustentar e ratificar sua narrativa anterior. Os discursos sociais sobre o abuso sexual infantil estão em processo de construção, porque somente há três décadas o tema tem sido mais frequentemente debatido nas universidades, nas organizações da sociedade civil, pelos órgãos públicos e pelos profissionais de educação, de saúde e da Justiça. A ausência de esclarecimentos e de produções científicas favoreceu o desenvolvimento de uma representação social do abuso sexual infantil elaborada com base no conhecimento de senso comum e que se incorporou aos pensamentos preexistentes sobre a sexualidade.

Todavia, a exigência social e jurídica de posicionamentos efetivos sobre a violência sexual contra crianças transformou as representações sociais relacionadas a essa temática. Tal reflexão encontra respaldo na afirmação de Jodelet (2001, p. 20) de que “(...) um acontecimento que surge no horizonte social, que não se pode mostrar indiferente, mobiliza medo, atenção e atividade cognitiva para compreendê-lo, dominá-lo e dele se defender". A partir da necessidade de responsabilização do abuso sexual infantil, bem como de sua discussão na mídia e nas universidades, é que os significados produzidos socialmente se transformaram.
Assim, ao atingir o âmbito da Justiça, as representações sociais da infância, da sexualidade e da violência, individualmente construídas pelos operadores do Direito, serão também incorporadas ao grupo em suas atuações profissionais. Na dependência de tais representações, está o trabalho dos profissionais que acolhem e encaminham a notificação do crime, buscando a verdade dos fatos e validando, ou não, o testemunho da vítima. Os discursos contidos nos autos processuais são importantes fontes de análise da atuação profissional e da expressão da representação social desse fenômeno, principalmente no grupo de profissionais que se relacionam diretamente com a criança na fase probatória do processo judicial.

O Estatuto da Criança e do Adolescente, no art. 2o, parágrafo único, considera “(...) criança, para efeitos desta lei, a pessoa de até doze anos de idade incompletos, e adolescente aquela entre doze e dezoito anos de idade". Baseado no princípio da Doutrina da Proteção Integral da Organização das Nações Unidas (ONU), tal Estatuto oportuniza a criança um tratamento jurídico diferenciado e protetivo, garantindo-lhe direitos contra a exposição e o constrangimento. Sob esse prisma, o presente trabalho discute a maneira como a Psicologia e o Direito convergem para a produção de novos procedimentos judiciais.

Os processos judiciais pesquisados evidenciam o valor do testemunho da criança, o qual é habitualmente questionado pelo Delegado de polícia, pelo Juiz de Direito, pelo Promotor de Justiça e pelo advogado do acusado, que, ao solicitarem o laudo pericial referente à veracidade das declarações infantis, expõem as dificuldades em reconhecer e enfrentar o fenômeno da vitimização sexual.

\section{Metodologia}

O objetivo desta pesquisa foi proporcionar uma revisão dos paradigmas jurídicos frente 
à problemática da criança vítima de abuso sexual, caracterizando as relações entre a infância e a instituição judiciária, na qual também está incluída a instituição policial. O enfoque principal foi o sistema de comunicação e notificação desse crime e as consequentes intervenções profissionais que buscam a validação do relato da criança.

A história contida em cada processo judicial não é apenas a do indivíduo que busca ou é forçado a buscar o serviço da Justiça mas também dos profissionais que nela atuam, como os Conselheiros Tutelares, os Delegados de polícia, os Promotores de Justiça, os Juízes de Direito, os médicos, os psicólogos e os assistentes sociais. Por tais motivos, a estratégia de pesquisa no acervo judiciário fornece base para uma generalização científica, com casos práticos que explicitam o fenômeno sob condições diferentes, sendo o estudo de casos múltiplos uma das metodologias mais adequadas a esse propósito.

A coleta de dados foi feita em situações cotidianas e na consulta aos autos processuais de crimes sexuais contra crianças, mediante a análise documental e sem os limites controlados de um experimento laboratorial ou da estrutura de um questionário. Assim, utilizando o estudo de casos, foi possível integrar os acontecimentos reais e cotidianos à linha de investigação traçada no projeto de pesquisa. Uma das vantagens do estudo de caso, e que se incorpora ao referencial teórico empregado, a teoria das representações sociais, é que as inferências da pesquisadora foram realizadas sobre algo que já ocorreu, sendo as evidências do caso questionadas e delimitadas por ela. Os processos judiciais foram usados como fonte de evidência para a análise documental e descrevem os casos, permitindo o desenvolvimento de proposições teóricas bem como a coleta e a análise dos dados.
A observação participante foi outra fonte de evidência utilizada, já que, como profissional da instituição judiciária, houve a participação da pesquisadora nos eventos investigados, oportunizando o acompanhamento dos procedimentos judiciais e as relações que se estabeleceram entre a instituição, a vítima e seus familiares. Tal participação ocorreu mediante as entrevistas no Fórum, a elaboração dos laudos periciais e as audiências, pois, atuando como profissional, estava inserida no cotidiano da instituição e nos grupos de profissionais. Essa modalidade ofereceu à pesquisadora a capacidade de perceber a realidade de alguém que está dentro do estudo de caso, de um ponto de vista interno, e não externo.

A importância da adoção de mais de uma fonte de evidências oferece credibilidade à pesquisa, visto que as informações foram corroboradas. A organização e a documentação dos dados também foram relevantes para proporcionar confiabilidade ao trabalho, destacando dos casos suas principais características e gerando um banco de dados para uma inspeção independente. A interpretação das informações aconteceu à medida que foram coletadas, verificando-se conjuntamente se as fontes de informação demonstravam contradição e se necessitavam de outras fontes para confirmá-las.

Os processos judiciais são documentos que registram um encadeamento de evidências sobre um determinado acontecimento nos quais existe conflito de interesses entre duas ou mais pessoas; por esse motivo, são referenciais importantes de investigação científica, revelando casos exemplares para um estudo completo. Na presente pesquisa, foram consultados 51 processos judiciais associados ao abuso sexual infantil e juvenil, pertencentes a três Comarcas de pequenas cidades do interior paulista. Os Juízes responsáveis pelas Varas Criminais em que se deu a pesquisa concederam 
autorização judicial para a consulta aos autos processuais, desde que resguardadas não só as identidades dos envolvidos como também dos profissionais que neles atuaram. Os critérios usados para a referência aos casos foram números aleatórios, em um recorte temporal dos anos de 2000 a 2006 e com a participação da Psicologia, mediante a escuta da vítima e a elaboração do laudo pericial. A idade das vítimas variou entre 03 e 14 anos, contados do período em que foi realizada a avaliação psicológica no Fórum, havendo a predominância do sexo feminino e da proveniência de meio sociocultural empobrecido.

Ainda que a ênfase do trabalho esteja voltada para a criança e não para o adolescente, constatou-se que alguns processos chegaram à Seção de Psicologia para a elaboração da avaliação psicológica quando a ocorrência do crime já ultrapassara dois anos, de modo que a vítima, que era criança na época do atentado, na data da entrevista, estava na adolescência. Outra situação observada foi que, em algumas situações, a denúncia formal ocorreu na adolescência, mas o processo abusivo continuado acontecia desde a infância. Nesse último caso, a narrativa e as recordações da vítima sofreram alterações não somente pelo tempo, mas também pelos conflitos internos típicos da fase em que se encontrava; todavia, para esta pesquisa, a importância está na atuação dos profissionais envolvidos e na confiabilidade que é dada ao discurso da vítima.

Os dois processos judiciais selecionados para o estudo de caso seguiram a lógica da replicação, pois, conforme Yin (2005, p.69), “(...) cada caso deve ser cuidadosamente selecionado de forma a prever resultados semelhantes (uma replicação literal) ou produzir resultados contrastantes apenas por razões previsíveis (uma replicação teórica)". Os dois casos eleitos para a análise individualizada expõem diferentes sistemas de notificação do abuso sexual e de encaminhamento da oitiva da vítima, em situações de contraste. No entanto, apresentaram características básicas semelhantes, como o sexo feminino, a idade das vítimas -07 e 08 anos -, o processo abusivo intrafamiliar, no qual o pai é o agressor, e a utilização da avaliação psicológica como parte do conjunto probatório. Ambos os casos ofereceram elementos para a explicitação dos procedimentos e atendimentos habituais às vítimas de abuso sexual infantil e para a necessidade e a possibilidade de modificá-los, e também evidenciaram as dificuldades relacionadas à confiabilidade no testemunho da criança. Através de um sistema comparativo, demonstraram como as condições de acolhimento da denúncia interferem na confirmação ou na retratação da criança do seu discurso inicial.

No caso 1, há características comuns à maioria dos casos pesquisados: a denúncia foi recebida pela Delegacia de Polícia e iniciado o inquérito policial; a vítima confirmou o abuso sexual em dois depoimentos na Delegacia; após a prisão temporária do réu e envio do inquérito ao Poder Judiciário, a vítima foi atendida pela psicóloga judiciária e desmentiu o atentado, durante a entrevista psicológica no Fórum; a genitora também modificou seu discurso, contradizendo em juízo seu depoimento na Delegacia; a vítima não foi ouvida em audiência, sendo determinada a avaliação psicológica no intuito de protegêla; a avaliação psicológica confirmou o abuso sexual, embora, na entrevista, a vítima o tenha desmentido; o Juiz de primeira instância absolveu o réu, alegando fragilidade no conjunto probatório e dúvidas diante do fato de a criança desmentir o abuso, na entrevista psicológica; há apelação do Ministério Público baseada no laudo psicológico; há acórdão reconhecendo o laudo como prova para a condenação do réu; o réu foi condenado em segunda instância. 
No caso 2, ainda que dentro da legalidade, a denúncia foi recebida de maneira incomum: a avaliação psicológica foi o primeiro procedimento empregado com a vítima; a denúncia foi recebida pela Vara da Infância e Juventude, e a vítima atendida no Fórum para a entrevista psicológica, sendo preservada da multiplicidade dos interrogatórios; confirmou o abuso sexual na entrevista com a psicóloga judiciária; a genitora e o acusado foram atendidos na Seção de Psicologia, no dia seguinte à denúncia, sendo cientificados de seu teor; o acusado confessou os atos libidinosos cometidos contra a criança, na entrevista psicológica, na Promotoria da Infância e Juventude e em audiência; o caso foi encaminhado à Vara Criminal; a vítima não foi ouvida na Delegacia de Polícia, somente em audiência no Fórum, mas em um momento em que se encontrava protegida e segura de ameaças; o Juiz de primeira instância condenou o acusado, utilizando a avaliação psicológica no conjunto probatório, sendo esse réu confesso; houve recurso do advogado do réu, requerendo a diminuição da pena imputada.

O modelo lógico de nível individual foi adotado para descrever o encaminhamento dos procedimentos que envolvem a vítima e as diferentes interferências que sofre a partir da revelação. A dinâmica dos acontecimentos foi representada em um fluxograma interativo entre os dois estudos de caso realizados, e a análise de conteúdo dos processos judiciais revelou o conjunto de evidências que colaboraram para o deslinde da ação judicial, salientando a importância da intervenção de cada profissional para a segurança da confirmação da violência pela vítima.

\section{Resultados}

Nos casos de abuso sexual infantil, o psicólogo é chamado a atuar no contexto judiciário devido às dificuldades implícitas que o tema sugere, uma vez que o testemunho da criança é percebido como frágil e passível de sofrer sugestões ou induções dos adultos envolvidos. O foco deste trabalho foi direcionado para a problemática vivenciada pela vítima, ao deslocar-se da clandestinidade da relação abusiva e enfrentar os questionamentos e os interrogatórios iniciados com a revelação à pessoa de sua confiança até os procedimentos judiciais decisórios.

A multiplicidade das intervenções institucionais foi observada nos 51 processos pesquisados, com enfoque na ausência de uma sistemática tanto para a escuta da vítima quanto para a inserção da Psicologia nos procedimentos judiciais, a qual está na dependência da atuação dos Magistrados e dos Promotores de Justiça. Os documentos contidos em cada processo judicial materializaram a passagem da criança pelas diferentes instâncias de atendimento e demonstraram as efetivas interferências em sua narrativa.

Os processos judiciais foram selecionados a partir da elaboração do laudo pericial, e, em 38 deles, os pareceres psicológicos apresentaram elementos favoráveis para a confirmação da vitimização sexual ou, ainda, para a vivência de uma relação de caráter abusivo na esfera da sexualidade. Nos demais processos, não houve parecer conclusivo de que a vítima apresentasse indicativos psicológicos de participação ou de exposição aos atos relatados. Nesses processos, as avaliações psicológicas mostraram não só a resistência e a negativa da criança em falar sobre o fato como também a ausência de indicadores psicológicos para vitimização sexual e/ou das características de um discurso próprio.

Os danos psicológicos produzidos na vítima podem ser atribuídos tanto às circunstâncias em que aconteceu o atentado quanto ao contexto de intervenção impositiva feita pela família e/ou por profissionais a que foi submetida após a revelação (Almeida, 2003; 
Gabel, 1992; Machado, 2003; Volnovich, 2005). Tal fato pôde ser constatado nas avaliações psicológicas pela análise do discurso e das reações da vítima, durante as entrevistas psicológicas, não se descuidando de averiguar as circunstâncias em que ocorreu a denúncia.

Os processos criminais consultados apresentaram, concomitantemente, características semelhantes e concorrentes, oferecendo parâmetros comparativos das diferentes formas de atuação profissional e sua interferência nos procedimentos judiciais. Tais documentos evidenciaram aspectos da representação social do abuso sexual infantil associada à crença na fragilidade do testemunho da criança e em sua suscetibilidade para a indução e para a fantasia, corroborando o que Moscovici (2007) afirma sobre as representações sociais servirem para familiarizar o não familiar. A crença na criança mentirosa, portanto, torna-se mais aceitável e menos perigosa, no sentido de induzir ao erro, do que a crença na realidade da prática de atos sexuais entre um adulto e uma criança.

Por outro lado, através do recorte temporal da pesquisa, foram notáveis os progressos nas manifestações que compõem os relatórios de inquérito policial, os requerimentos dos Promotores de Justiça e as determinações dos juízes de Direito frente aos casos de abuso sexual infantil. Os registros ressaltaram a aceitação de que a Psicologia traz uma compreensão específica da infância e da sexualidade capaz de auxiliar no deslinde adequado das ações judiciais e de promover um atendimento não revitimizante.

Há uma predominância, nos casos pesquisados, do reconhecimento do Promotor de Justiça e do Juiz de Direito da necessidade da intervenção de um profissional habilitado e familiarizado com o trato da infância, identificado no psicólogo judiciário. Ainda que esse posicionamento confirme a efetiva participação da Psicologia, nos procedimentos afetos aos crimes sexuais cometidos contra a criança, não há regularidade e uniformidade de condições especiais e protetivas para a oitiva da vítima. Observa-se, todavia, que há um movimento das autoridades judiciárias em preservar a criança do constrangimento e da revitimização, admitindo o desconforto e a inadequação das condições oferecidas na audiência para a tomada de seu depoimento.

Os dois casos judiciais escolhidos como exemplares e estudados neste trabalho exibiram em seu conteúdo um conjunto de ações que demonstram as dificuldades reais enfrentadas no contexto judiciário, no qual também se inclui o contexto policial. Os trâmites judiciais são complexos e se diferenciam entre as Comarcas, alterando as relações de trabalho estabelecidas em cada Fórum.

Averiguou-se que há uma constância de terminologias empregadas nos Boletins de Ocorrência e nos depoimentos nas Delegacias de Polícia que revelam um discurso que não é o da criança, mas o do interlocutor. As inquirições são descritas sem um esclarecimento acerca das condições em que foram realizadas as entrevistas investigativas, não deixando de salientar, entretanto, que foram realizadas na presença do responsável legal, já que é o procedimento exigido.

A crença de que a experiência do abuso sexual causa danos psicológicos à criança interfere igualmente na intervenção jurídica, visto que se espera da vítima um conjunto de características padronizado pela literatura especializada, baseada nos padrões norteamericanos de conduta e, quando isso não é constatado, a tendência é desacreditá-la. Observou-se que as avaliações psicológicas somente foram validadas como prova técnica nos processos judiciais, quando 
constataram danos psicológicos ou reações potencializadas nas vítimas, ou mesmo quando ratificaram os depoimentos documentados nos autos processuais.

Contudo, nos casos em que a vítima não apresentou danos, os laudos psicológicos apontaram as características da narrativa da criança a respeito do atentado sexual que evidenciam as interferências das circunstâncias em que se efetivou o processo abusivo. A representação do agressor na vida da vítima é outro fator a ser considerado, pois, em alguns dos casos, os profissionais que acolheram as denúncias foram surpreendidos pela reação emotiva de compaixão e afeto da vítima em relação ao agressor, levando-os a descrer de suas palavras. Percebe-se que a representação social do abuso sexual infantil está vinculada ao sofrimento psicológico da vítima, porém, a Psicologia enfrenta o desafio de elaborar uma análise que, ao mesmo tempo em que beneficia a criança, oferece subsídios para a decisão judicial.

Os processos judiciais deixam claro que, no âmbito judiciário, além de toda a complexidade do testemunho da criança vítima de abuso sexual, há a necessidade da responsabilização penal do acusado. Assim, são evidentes as falhas nas práticas judiciárias relativas ao acolhimento do testemunho da criança, que urgem por mudanças beneficiárias tanto para a vítima como para os profissionais, sem ferir a aplicabilidade da lei.

A representação social da infância está realçada no processo social e judicial em que a criança é inscrita, quando rompe o silêncio e traz à tona fatos difíceis de serem ouvidos. Por força de um sistema de crenças, a palavra da criança é desvalorizada não apenas pela família mas também pelos agentes judiciais no momento do acolhimento da denúncia, de sorte que o que já era difícil se torna insuportável para ela, podendo levá-la a desmentir o que havia dito anteriormente. Quando a criança traz a um adulto uma narrativa capaz de alterar a dinâmica dos relacionamentos, é, imediatamente, resgatada a dúvida a propósito da veracidade de sua fala, já que a fragilidade está incorporada à representação social da infância. As pressões para que a criança fale a verdade, alertando-a sobre a gravidade das consequências do que declarou, na maioria das vezes reprime sua espontaneidade e segurança em relatar os fatos vividos, sendo esse um fator que leva ao descrédito (Gabel, 1992; Machado, 2002; Mello, 2006).

Dentro desse contexto, percebe-se que, na sala de audiências, é comum as crianças se mostrarem retraídas, pouco receptivas e com discurso lacônico, bem como nas Delegacias de Polícia se revelarem assustadas e pouco elucidativas diante da intensidade dos interrogatórios e da presença de várias pessoas. A participação do psicólogo nesses procedimentos é fundamental para a oferta de uma escuta especializada e protetiva, porque, conforme Volnovich (2005), mesmo com a criança provida de direito à participação nos assuntos relativos à sua vida, há uma tendência dos adultos em desconsiderar tal fato, o que dificulta ainda mais a maneira como se preparam para ouvi-la. Aceitar que a criança possui percepção e opinião sobre as pessoas e os acontecimentos de sua vida é o primeiro passo para compreendê-la e oferecer-lhe uma escuta adequada.

Quando se questiona a validade do testemunho de uma criança no contexto judiciário, é fundamental a reflexão sobre a forma como a criança é recebida nas diferentes instituições, quando quebra o segredo da clandestinidade de uma relação abusiva e busca coragem para libertar-se do jugo daquele que a aprisiona. Constatou- 
De acordo com Salles (1991), a ideologia se concretiza nas representações sociais, e é expressa no exterior, no mundo, pelas ações e pela linguagem das pessoas. se, nesta pesquisa, que a fragilidade do testemunho da criança está relacionada aos modos de acolhimento da denúncia do abuso sexual, e não propriamente ao seu depoimento, pois, mesmo antes do enfrentamento dos procedimentos judiciais, ela se depara com a surpreendente reação de seus familiares e começa a sofrer um calvário de interrogatórios.

As fontes de notificação do abuso sexual infantil iniciam-se pela revelação da criança à família, à vizinhança ou à escola, e, passado o embaraço que envolve os adultos escolhidos e a reflexão destes sobre a atitude a ser tomada, ela é encaminhada à Delegacia de Polícia e/ou ao Conselho Tutelar. Na Delegacia, é feito o Boletim de Ocorrência, e, tomado o depoimento da vítima, na presença de seus responsáveis legais e/ou na de um Conselheiro Tutelar, começa a investigação do caso e o posterior encaminhamento ao Poder Judiciário.

Habitualmente, os casos são encaminhados à Delegacia de Defesa da Mulher e, quando as evidências revelam a veracidade do abuso sexual, esse órgão encaminha a vítima ao Instituto Médico Legal (IML) para o Exame de Corpo de Delito, onde é realizada a avaliação ginecológica da menina e anal do menino. Tal exame quase sempre coopera para a incredulidade na palavra da criança, já que os atos libidinosos não deixam marcas físicas.

Outro encaminhamento realizado e existente em alguns Municípios são os programas de atendimento às vítimas, que pertencem à Secretaria de Saúde e têm o objetivo de orientar sobre a prevenção das doenças sexualmente transmissíveis. Nota-se, portanto, que a vítima é submetida a algumas intervenções, no decorrer do inquérito policial, incomuns ao seu cotidiano, que a assustam e surpreendem pelo grau de informações e pela percepção da gravidade dos atos a que foi submetida. Foi observado que os procedimentos da investigação do abuso sexual infantil envolvem igualmente técnicos e profissionais que atuam direta e indiretamente com a criança, formando um conjunto interdisciplinar, mas que, não necessariamente, têm suas atividades vinculadas e equiparadas.

Os casos 1 e 2 foram descritos e analisados de maneira cruzada, seguindo-se as fases dos processos judiciais a que pertencem, contextualizando a criança vítima de abuso sexual e os profissionais interlocutores nos procedimentos judiciais. A exposição e a discussão dos casos foram feitas simultaneamente à análise das práticas discursivas que compõem os processos judiciais e as diferentes intervenções e procedimentos a que as vítimas foram submetidas, desde a denúncia na Delegacia de Polícia até a sentença judicial em primeira e em segunda instâncias.

No caso 1, a inculpação do réu seguiu uma dispendiosa trajetória, bem como a multiplicidade das intervenções à vítima contribuiu para que esta se sentisse insegura e retificasse seu depoimento inicial, o que não somente lhe causou prejuízos emocionais como também dificultou o trabalho da Justiça. Há de se salientar as dimensões psicológicas das atuações profissionais, neste caso, relacionando-as à forma como cada profissional, individualmente, assimila a realidade social, influenciado por um processo histórico e ideológico que determina seu modo de pensar e de agir. De acordo com Salles (1991), a ideologia se concretiza nas representações sociais, e é expressa no exterior, no mundo, pelas ações e pela linguagem das pessoas.

Nesse caso, constataram-se dois tipos de posturas distintas: a do Juiz de primeira instância, que optou por manter-se apegado apenas às normas jurídicas, a da genitora da vítima, que preferiu revitimizar a filha, 
imputando-lhe o papel de mentirosa diante da exposição social e, obviamente, o defensor do réu, que, aproveitando-se das contradições, construiu a defesa. De outro lado, encontram-se os demais profissionais, Promotor de Justiça, psicóloga, Procurador de Justiça e Desembargadores, que utilizaram outros referenciais e representações para a análise do abuso sexual, em uma clara valorização da palavra inicial da vítima e das subjetividades contempladas na avaliação psicológica bem como nas intercorrências que a antecederam. Ainda que a criança tenha retificado seu discurso relativo ao depoimento na Delegacia de Polícia, durante a entrevista psicológica, suas atitudes, reações e indicativos psicológicos foram considerados compatíveis com aqueles comumente apresentados pelas vítimas de crimes sexuais.

No caso 2, não há a incredulidade na palavra da vítima, nem mesmo da denunciante, pois as condições foram facilitadoras não só para a criança mas também para a confissão do acusado. A interação entre os profissionais e, principalmente, a disponibilidade do Juiz em oferecer condições para o acolhimento do testemunho infantil foram essenciais para a preservação e a proteção da vítima, assim como para o deslinde rápido e eficiente da ação judicial.

A lógica possível das intervenções demonstrou a função de cada profissional e dos familiares da vítima; o caso 2, portanto, mostra que a realização da escuta da vítima pelo psicólogo pode substituir a oitiva formal de uma tomada de depoimento, na Delegacia de Polícia e na audiência judicial, o que evita o atendimento revitimizante e preserva seu discurso, uma vez que não há a necessidade de múltiplos interrogatórios. Entretanto, para tal escuta especializada, deverão ocorrer alterações na sistemática do acolhimento da denúncia, na qual a inserção da Psicologia se dará imediatamente, após o início das intervenções. Dessa forma, a atuação do psicólogo judiciário oferece tanto uma substituição para a oitiva formal da criança em audiência quanto um espaço diferenciado para que ela se expresse sem constrangimentos. Nos casos 1 e 2, a avaliação psicológica foi empregada como parte do conjunto probatório, mas determinada em fases processuais distintas, o que interferiu sobremaneira no discurso da criança. Tal fato pode ser observado no caso 1, no qual o Juiz não aceitou o parecer favorável da avaliação psicológica, em virtude de a vítima não haver confirmado literalmente o abuso sexual sofrido, mas, em segunda instância, o laudo psicológico foi reconhecido como prova.

No primeiro caso, a Psicologia trabalhou no sentido de desconstruir a representação social do abuso sexual pautado na incredulidade do testemunho da criança, utilizando-se de recursos técnicos e teóricos para trazer à luz o discurso latente da vítima, justificando sua retratação. No segundo caso, as ações precederam as concepções da representação social do abuso sexual infantil, e a Psicologia pôde atuar com liberdade sobre as demandas psíquicas da vítima, preservando-a da revitimização dos múltiplos interrogatórios.

\section{Discussão}

A pesquisa demonstra que, nos crimes sexuais, a palavra da criança tem real importância, visto que, em sua vivência infantil, usa uma linguagem que traduz as relações estabelecidas com os membros familiares e com seus pares no grupo social a que pertence. As avaliações psicológicas contidas nos processos judiciais valorizam a palavra infantil, pois, conforme as vítimas a utilizam revelam não somente seu grau de maturidade psíquica mas também a intensidade de sua compreensão da sexualidade humana e da estimulação social que recebe sobre tal temática. A nomeação dada pela criança aos órgãos genitais, aos toques ou ao ato sexual a que foi submetida expõe as influências que sofreu em sua narrativa, se espontânea 
ou se construída por pressão ou indução de um adulto.

Assim, deve-se evitar a validação do testemunho da vítima através da comparação de seu depoimento tomado em uma Delegacia de Polícia com aquela analisada em um laudo psicológico, conforme ocorreu no caso 1. O Juiz de primeira instância, baseando-se nas contradições do que estava escrito nos documentos, desconsiderou as técnicas e as teorias empregadas no laudo pericial. A desvalorização efetiva do discurso da criança se materializa quando entra no âmbito jurídico, e, apesar do grande avanço advindo do Estatuto da Criança e do Adolescente, a prática ainda comprova a insegurança dos profissionais em renunciar ao ideário da criança propensa à fantasia e à indução em sua retórica. Quando vítima e testemunha compõem a mesma personagem na lide jurídica, torna-se evidente a dificuldade a ser enfrentada pelas autoridades judiciárias responsáveis pelo caso, sobretudo quando se trata de uma vítima criança.

O caso 2 revelou que o acolhimento adequado e cuidadoso das palavras da criança e o incentivo para que apresente suas ideias e percepções são fundamentais para que se sinta segura e produza um discurso claro, coerente e próprio. Mediante tal estratégia, valorizou-se a palavra da criança, oportunizando-lhe um fluxo de comunicação com a Justiça capaz de garantir seu direito de se expressar livre da opressão.

Conforme explicita Gabel, “(...) o abuso sexual praticado contra a criança é uma das formas de maus-tratos que mais se ocultam: a criança tem medo de falar e, quando o faz, o adulto tem medo de ouvi-la" (1997, p.11). Esse pressuposto define a realidade que envolve a maioria dos casos que chegam ao Poder Judiciário e justifica o fato de a vítima desmentir em juízo o que afirmara na família ou em uma instituição. No entanto, a Psicologia considera que não apenas o que é dito verbalmente aponta caminhos para esclarecer as dúvidas ou as suspeitas, mas também o comportamento não verbal. Assim, inserir a avaliação psicológica no início dos procedimentos judiciais favorece tanto a expressão quanto a proteção da vítima.

Grande parte dos profissionais envolvidos nos processos de crimes sexuais de vítimas crianças não recebe capacitação específica para realizar os procedimentos necessários, sendo nítido, na análise dos processos judiciais, o despreparo desses profissionais para ouvi-las. Os casos 1 e 2 evidenciaram dois sistemas de notificação distintos, que fizeram o diferencial não só em relação ao tempo despendido no processo de responsabilização do réu como também às intervenções diretas e indiretas no testemunho da criança.

Embora, no caso 1, a vítima não tenha sido ouvida em audiência pelo Juiz e a avaliação psicológica tenha sido reconhecida como substituta para a oitiva, a demora em formalizar a denúncia e a tomada de declarações na Delegacia de Polícia e no Conselho Tutelar, assim como a intervenção do IML, contribuíram para prejudicar o seu testemunho, já que este desmentiu o ato incestuoso na entrevista psicológica. Em contrapartida, no caso 2, a vítima foi isentada das intervenções anteriores e ofereceu um testemunho próprio, sendo resguardado seu direito de participação pessoal nos procedimentos através de uma escuta não revitimizante.

A figura a seguir explicita os dois sistemas de notificação e o encadeamento das intervenções sofridas pelas vítimas, sendo que a linha pontilhada indica a diferenciação da trajetória do caso 2 em relação à do caso 1 . 


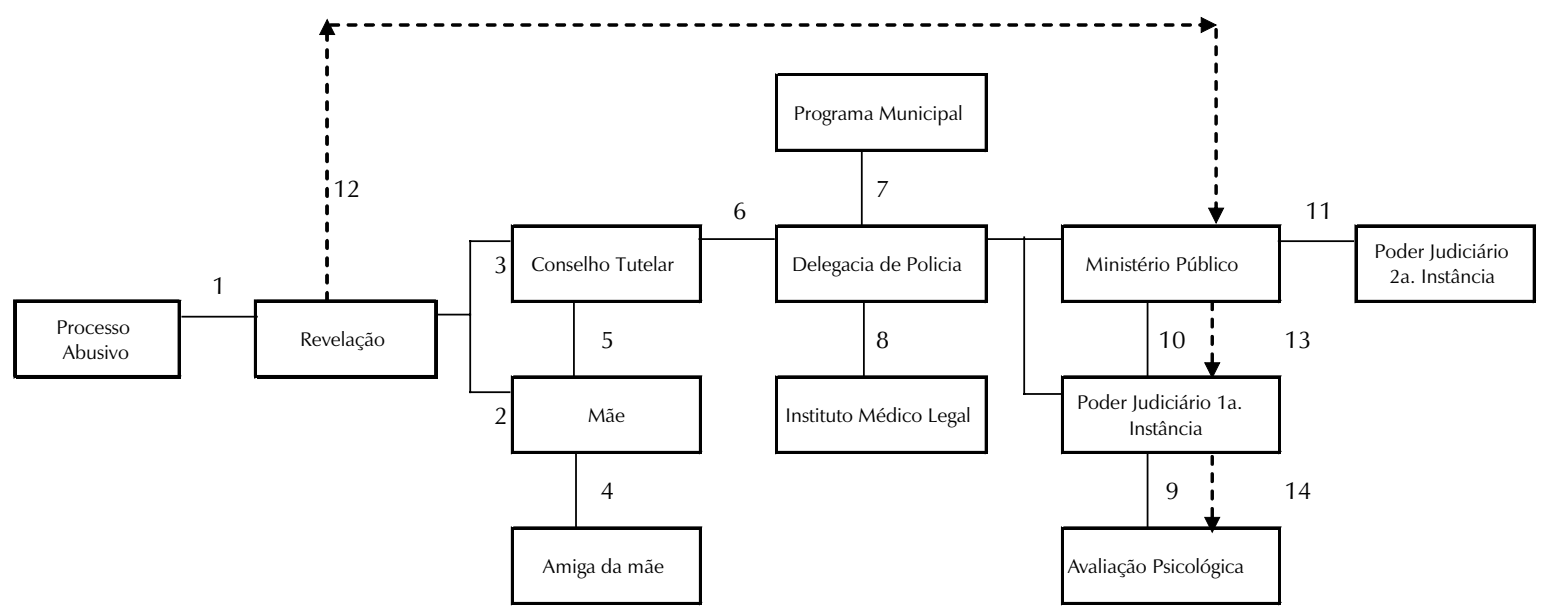

Figura 1. Fluxograma do sistema de notificação

1 Nos casos 1 e 2, a vítima revelou o abuso sexual a uma pessoa de sua confiança, sofrendo a primeira intervenção 2 Intervenção da mãe no caso 1

3 Intervenção do Conselheiro Tutelar no caso 1

4 Intervenção da amiga da mãe no caso 1

5 Intervenção do Conselheiro Tutelar junto à mãe, gerando mais um canal de intervenção, porém no contexto familiar da vítima

6 Interrogatório na Delegacia de polícia no caso 1

7 Nenhum dos dois casos sofreu essa intervenção, mas há a possibilidade

8 Atendimento no Instituto Médico Legal no caso 1

9 Entrevista psicológica no Fórum no caso 1: vítima desmentiu

10 Juíz não aceitou a confirmação do laudo psicológico para abuso sexual pelo fato de a vítima desmentir no caso 1

11 Apelação do Ministério Público ao Egrégio Tribunal: decisão condenatória no caso 1

12 A avó da vítima denuncia ao Ministério Público, no caso 2

13 O Poder Judiciário e o Ministério Público acolhem a denúncia no caso 2

14 A avaliação psicológica é a primeira intervenção profissional à vítima no caso 2, havendo a probabilidade de ser a única

Fonte: Dados extraídos dos processos judiciais referentes aos casos 1 e 2

O fluxograma relativo ao caso 1 aponta o caminho habitual de todos os casos consultados, havendo pequenas variações entre um e outro em função das peculiaridades relativas a cada caso. O Exame de Corpo de Delito é solicitado na maioria dos casos, sendo um procedimento rotineiro quando a denúncia ingressa na Delegacia de Polícia, como também o encaminhamento da vítima aos programas municipais de saúde e social.

Entretanto, o fluxo relacionado ao caso 2 não foi constatado em nenhum dos outros 50 casos consultados, sendo único. Nesse caso, o testemunho da criança esteve isento de interferências anteriores à avaliação psicológica, o que contribuiu para sua credibilidade, porém, a vítima foi inquirida em audiência pelo Juiz. Observa-se que a oitiva da vítima pelo Juiz poderia ser evitada, já que, no caso 1, tal fato não ocorreu e, mesmo assim, não invalidou nenhum dos procedimentos.

A comparação dos dois casos revela que a busca da verdade, tantas vezes focada no discurso da criança e nas contradições típicas da infância, deverá levar em conta o conjunto de práticas discursivas de seus interlocutores, o qual é incorporado no decorrer do processo judicial. No cotidiano das práticas judiciárias, quando se trata de busca ou de pesquisa da verdade, seja nos processos, seja nas audiências ou nos discursos, é como se o sujeito trouxesse com ele enigmas pessoais a serem 
decifrados, como se o contexto judiciário e a sociedade fossem neutros na produção da verdade.

A participação da Psicologia nos procedimentos judiciais traz a observação direta do que a criança diz e faz, ensina a compreendê-la, gerando a possibilidade de reconhecimento das características da fase desenvolvimental em que se encontra e as referências do contexto sociocultural em que vive. A exposição dos casos, através do fluxograma, evidencia que o momento da inserção da Psicologia nos procedimentos judiciais é favorecedor de uma leitura psicológica eficaz e de uma perícia adequada que exerça, além de sua função de assessorar a decisão judicial, a função de proteger a criança.

O Delegado de polícia, ao apresentar um relatório de inquérito policial ao Poder Judiciário, compõe uma narrativa baseada em diferentes informações investigativas e também nas declarações da vítima-criança. Tal relatório, recebido pelo Promotor de Justiça, passa a incorporar o discurso deste e, junto a outras informações, concilia sua manifestação enviada ao Juiz de Direito, o qual, por sua vez, registra todos os dados colhidos até então e reproduz alguns dos procedimentos já desenvolvidos, como, por exemplo, a tomada de declarações da vítima. Nessa dinâmica é que a representação social do abuso sexual infantil se fortalece ou se transforma, o que pode ser verificado nas atuais discussões sobre o atendimento não revitimizante às vítimas, nas quais os Tribunais de Justiça do País se mostram envolvidos e comprometidos. Segundo aponta Moscovici (2007, p.21), “(...) é durante o processo de transformação que os fenômenos são mais facilmente percebidos", conforme se observa nas pesquisas e produções bibliográficas que apontam a valorização da escuta da criança em situação judicial.

\section{Conclusão}

O testemunho da criança vítima é um dos recursos judiciais utilizados na produção de provas, em um processo crime, e é de relevância, visto que nos crimes sexuais, na maioria dos casos, a vítima é também a única testemunha. A tendência dos operadores do Direito em descrer do testemunho da criança está vinculada não somente ao fato de esta desmentir o que dissera anteriormente, mas também à representação social do abuso sexual infantil que permeia as atuações dos profissionais. Tal fato foi constatado no caso 1, e nota-se que, ao desmentir o fato, a vítima encontrou maior receptividade do que quando manteve a acusação, seja na família, seja no meio jurídico.

As experiências positivas em Comarcas menores comprovam que é possível a mudança nos procedimentos judiciais sem ferir a lei e proteger a criança, como, por exemplo, quando a denúncia chega à Promotoria de Justiça e é imediatamente encaminhada à Seção de Psicologia para a escuta da criança, não havendo a intervenção de outros profissionais, evitando, assim, a revitimização, como foi explicitado no caso 2. A avaliação psicológica contida nos processos criminais relativos ao abuso sexual infantil, além de assessorar uma decisão judicial, tem por finalidade transformar a representação social do abuso sexual infantil. Percebe-se, com isso, uma real possibilidade de mudança de paradigmas jurídicos e da relação entre os operadores do Direito e a criança, pois a instituição judiciária contém, em seus arquivos e 
documentos, registros de eventos reais. Cada processo judicial, portanto, é um caso que contém uma história pessoal e que necessita de uma intervenção institucional para a resolução de um conflito de cuja conjuntura a Psicologia participa. Além de oferecer uma escuta subjetiva à vítima, o psicólogo jurídico elabora um documento fundamentado em técnicas e teorias que priorizam sua proteção integral.

Nas últimas décadas, a violência sexual infantil ganhou visibilidade social, o que é um resultado das mudanças ocorridas nos diferentes setores da sociedade. "Esse crescente interesse pelo abuso sexual de crianças é, assim, sem dúvida, o resultado de crianças com maior liberdade de expressão e também de adultos mais dispostos a ouvi-las" (Almeida, 2003, p. 119).

Tal fato pode ser constatado nos tribunais do País, diante do crescente número de inquéritos policiais e ações judiciais que ingressam na Justiça por diferentes vias de acesso, o que vem confirmar a importância da existência de atuações articuladas em rede e da interlocução das instituições responsáveis pela proteção e defesa das crianças e adolescentes.

As discussões sobre o atendimento não revitimizante à criança já são uma realidade nos tribunais, e a imprescindibilidade da interação entre as Varas da Infância e da Juventude e as Varas Criminais promove a celeridade da proteção à vítima e o deslinde adequado da ação judicial. Ao redigir um documento ao Poder Judiciário, o profissional perito deve ter em mente, além da preservação da ética e do compromisso com a verdade, que está diante da oportunidade de intervir nos procedimentos judiciais concernentes ao abuso sexual infantil, já que propicia conhecimentos específicos que devem ser contextualizados à realidade da criança atendida. Há uma constante construção do processo de atendimento às vítimas no contexto judiciário, que se pode perceber pela evolução não somente dos laudos psicológicos, mas também das determinações judiciais fundamentadas nas peculiaridades da infância.

É inegável que as práticas discursivas contidas nos processos judiciais produzem conhecimentos e retratam as relações estabelecidas, não somente entre a instituição judiciária e a infância, mas também entre os diferentes profissionais. As transformações apontadas nesta pesquisa, atinentes aos discursos tanto da Psicologia quanto do Direito, materializam as boas perspectivas para mudanças no sistema de notificação do abuso sexual infantil, que engloba igualmente o Sistema de Garantia de Direitos para a proteção das vítimas. Certamente, os profissionais que atuam nos crimes sexuais contra crianças se mostram mais motivados e atentos para as complexas características que envolvem esse fenômeno, assim como para o reconhecimento da necessidade de um programa de capacitação aos profissionais. Novas relações se estabelecem, surgem novos olhares sobre a criança vítima e inicia-se uma nova etapa de práticas responsáveis.

Há de se observar que a prática discursiva dos operadores do Direito propicia referências para novas práticas, sendo referendada nas apelações e jurisprudências que apoiam outros julgamentos. Os Magistrados e Promotores, na particularidade de suas funções, constroem significados que 
embasam as decisões de outros profissionais, o que pressupõe o desenvolvimento de representações. Moscovici, (2007) observa que todas as interações humanas que surjam entre duas pessoas ou dois grupos caracterizam representações sociais, as quais se desenvolvem através do processo de tornar familiar o que não é familiar. Assim, as informações transitam entre os grupos por intermédio das representações dadas aos eventos, às pessoas, aos acontecimentos, levando os indivíduos à busca de significados para o que observam ou vivenciam. As apelações e as jurisprudências materializam as práticas, exemplificando as diferentes formas de atuação dos Magistrados julgadores de segunda instância bem como a trajetória da produção da verdade jurídica.

A avaliação psicológica é um instrumento eficaz e propulsor para modificações nos procedimentos judiciais, incorporando à prática discursiva do contexto judiciário críticas e esclarecimentos. Um parecer assertivo e explicativo oferece fundamentos para os Magistrados e Promotores construírem suas convicções, além da busca de novos recursos para a oitiva da vítima, com o intuito de protegê-la, de validar seu testemunho e de promover sentenças eficazes e justas. Mesmo que seja visível a evolução no comprometimento das autoridades judiciárias em oferecer melhores condições de escuta à criança, a revitimização ainda ocorre, por não haver uma regularidade nos sistemas de notificação dos crimes sexuais.

Esta pesquisa evidencia que a fragilidade da palavra da criança está na maneira como é acolhida pelos adultos, desde a revelação na família até a denúncia aos órgãos oficiais, demonstrando a urgência de capacitação dos profissionais que atuam nos crimes de abuso sexual infantil, para os quais a Psicologia, embora já tenha conquistado um espaço efetivo e relevante, indubitavelmente ainda tem muitas contribuições a dar.

\section{Consuelo Biacchi Eloy}

Mestrado em Psicologia pela Universidade Estadual Júlio de Mesquita Filho, Assis-SP, Brasil (2007)

Psicóloga Judiciária do Tribunal de Justiça do Estado de São Paulo, Brasil.

E-mail: consueloeloy@hotmail.com

Endereço para envio de correspondência:

Rua do Expedicionário, 1895 - Jardim Matilde,Ourinhos - SP- Brasil. CEP 19.902-610

Recebido 14/11/2009, 1a Reformulação 12/10/2011, Aprovado 15/10/2011 
Almeida, A. C. E. P. (2003). Abuso sexual de criança: crenças sociais e discursos da psicologia. Dissertação de mestrado em Psicologia e Justiça, Instituto de Educação e Psicologia, Universidade do Minho, Braga, Portugal.

Gabel, M. (Org.). (1992). Crianças vítimas de abuso sexual. São Paulo: Summus.

Jodelet, D. (2001). Representações sociais: um domínio em expansão. In D. Jodelet. As representações sociais. Rio de Janeiro: Ed. UERJ.

Brasil. (1990). Estatuto da Criança e do Adolescente (Lei n. 8.069). Brasília, DF. Recuperado em 12 de outubro de 2011 de www. planalto.gov.br/ccivil_03/leis/L8069.htm.

Machado, C. (2002). Abuso sexual de crianças. In C. Machado, \& R. A. Gonçalves. Violências e vítimas de crimes. Coimbra, Portugal: Quarteto.

Mello, R. P. (2006). A construção da noção de abuso sexual infantil. Belém, PA: EDUFFA.
Moscovici, S. (2007). Representações sociais: investigações em psicologia social (5a. ed.). Petrópolis, RJ: Vozes.

Salles, L. M. F. (1991). Representação social e o cotidiano. São Paulo: Didática.

Volnovich, J. R. (Org.), (2005). Abuso sexual na infância. Rio de Janeiro: Lacerda.

Yin, R. K. (2005). Estudo de caso: planejamento e métodos. Porto Alegre: Bookm. 